\title{
Modified difficult index adding extremely difficult for fully impacted mandibular third molar extraction
}

\author{
Jae-Young Kim, Hae-Sung Yong, Kwang-Ho Park, Jong-Ki Huh \\ Department of Oral and Maxillofacial Surgery, Gangnam Severance Hospital, Yonsei University College of Dentistry, Seoul, Korea
}

\begin{abstract}
J Korean Assoc Oral Maxillofac Surg 2019;45:309-315)
Objectives: The aim of this study was to evaluate the validity of the existing classification and difficulty index of impacted mandibular third molars in clinical situations and propose a more practical classification system.

Materials and Methods: This study included 204 impacted mandibular third molars in 154 patients; panoramic x-ray images were obtained before tooth extraction. Factors including age, sex, and pattern of impaction were investigated. All impacted third molars were classified and scored for spatial relationship (1-5 points), depth (1-4 points), and ramus relationship (1-3 points). All variables were measured twice by the same observer at a minimum interval of one month. Finally, the difficulty index was defined based on the total points scored as slightly difficult (3-4 points), moderately difficult (5-7 points), very difficult (8-10 points), and extremely difficult (11-12 points).

Results: The strength of agreement of the total points scored and difficulty index were 0.855 and 0.746 , respectively. Most cases were classified as moderately difficult $(73.0 \%)$. Although only 13 out of 204 cases $(6.4 \%)$ were classified as extremely difficult, patients classified as extremely difficult were the oldest $(P<0.05)$.

Conclusion: For difficulty classification, the authors propose one more difficult category beyond the existing three-step difficulty index: the clinician should consider the patient's age in the difficulty index evaluation.
\end{abstract}

Key words: Third molar, Tooth extraction, Impacted tooth, Classification

[paper submitted 2019. 7. 22 / revised 1st 2019. 9. 25, 2nd 2019. 10. 10 / accepted 2019. 11. 2]

\section{Introduction}

Extraction of impacted third molars is one of the most common procedures performed by oral and maxillofacial surgeons. It is important to evaluate the difficulty of the extraction in an outpatient clinic because this will allow prediction of the duration of the procedure and appointment time with the patient. Moreover, the pattern of the impacted third molar and difficulty of extraction are known to be associated with postoperative complications ${ }^{1,2}$.

In the Korean insurance system, "full impaction state" is

\section{Jong-Ki Huh}

Department of Oral and Maxillofacial Surgery, Gangnam Severance Hospital, Yonsei University College of Dentistry, 211 Eonju-ro, Gangnamgu, Seoul 06273, Korea

TEL: +82-2-2019-4560 FAX: +82-2-3463-4052

E-mail:omshuh@yuhs.ac

ORCID: https://orcid.org/0000-0002-7381-3972

(2) This is an open-access article distributed under the terms of the Creative Commons Attribution Non-Commercial License (http://creativecommons.org/ licenses/by-nc/4.0/), which permits unrestricted non-commercial use, distribution, and reproduction in any medium, provided the original work is properly cited.

Copyright (C) 2019 The Korean Association of Oral and Maxillofacial Surgeons. All rights reserved. defined as impaction of more than two-thirds of the crown of the third molar in the alveolar bone. However, not all full impaction states represent the same degree of extraction difficulty. In some clinical cases, fully impacted third molars can be extracted relatively simply by removing the alveolar bone and splitting the teeth; in others, the molar is so deeply impacted that general anesthesia is required.

These severely displaced teeth are often accompanied by pathologic changes of the surrounding tissue where the difficulty of tooth extraction is much higher. However some report severely displaced impacted third molars that are neither cystic nor tumorous ${ }^{3,4}$.

Pell and Gregory ${ }^{5}$ and Winter ${ }^{6}$ reported a classification system to predict the difficulty of an impacted third molar extraction. A recent difficulty index was recently proposed by Pederson ${ }^{7}$ based on Winter's classification ${ }^{6}$ and the Pell and Gregory classification ${ }^{5}$, but all the variables were not included (Note: Reference No. 7 is quoted by the article of Koerner $^{8}$. The book is out of print $)^{7-9}$. For example, there is no consideration for an inverted tooth when evaluating the difficulty index. According to Gbotolorun et al. ${ }^{10}$, "depth from 
point of elevation" is a significant factor to consider when estimating the difficulty of extraction. In previous classifications, however, there is also a lack of detailed consideration for teeth that are deeply impacted, such as a description of which part of the crown of the impacted third molar is located

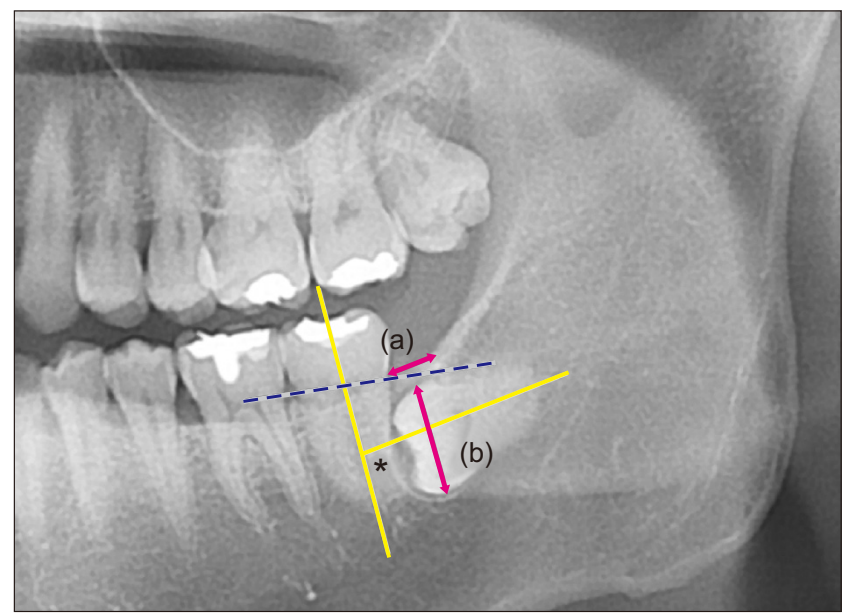

Fig. 1. Measurement and classification of the impacted third molar. Spatial relationship was classified based on the angle measured between the long axis of the impacted third molar and adjacent second molar (yellow line and an asterisk mark). Depth was classified based on the line connecting the cervico-enamel junction (CEJ) of the adjacent second molar (dotted blue line). Ramus relationship/space available was subcategorized based on the ratio between the distance from the ascending ramus to the distal of second molar (a) and the diameter of the impacted third molar (b) (pink arrows).

Jae-Young Kim et al: Modified difficult index adding extremely difficult for fully impacted mandibular third molar extraction. J Korean Assoc Oral Maxillofac Surg 2019 underneath the root of the adjacent second molar. Therefore, further studies are necessary to determine how to fully evaluate the difficulty of an impacted third molar extraction ${ }^{8-12}$.

The purpose of this study was to evaluate the validity of the existing classification system and difficulty index of the impacted mandibular third molars in clinical situations and propose a more practical classification system.

\section{Materials and Methods}

This study included patients visiting the Department of Oral and Maxillofacial Surgery, Gangnam Severance Hospital from January to December 2017 for third molar examination and undergoing an impacted mandibular third molar extraction. A third molar was considered impacted when more than two-thirds of its crown was impacted in the alveolar bone. Patients were excluded if they were below 19 years of age, had a displaced mandibular third molar with cystic lesions, or had undergone panoramic x-ray imaging at another hospital. Ultimately, 154 patients with 204 impacted mandibular third molars were selected.

All patients underwent panoramic x-ray imaging before extraction. Based on the panoramic $\mathrm{x}$-ray image, the impacted mandibular third molar was evaluated for three major parameters: spatial relationship, depth, and ramus relationship/ space available ${ }^{7-9}$. This retrospective study was approved by the Institutional Review Board of the Gangnam Severance Hospital (approval No. 3-2019-0118), and the informed con-
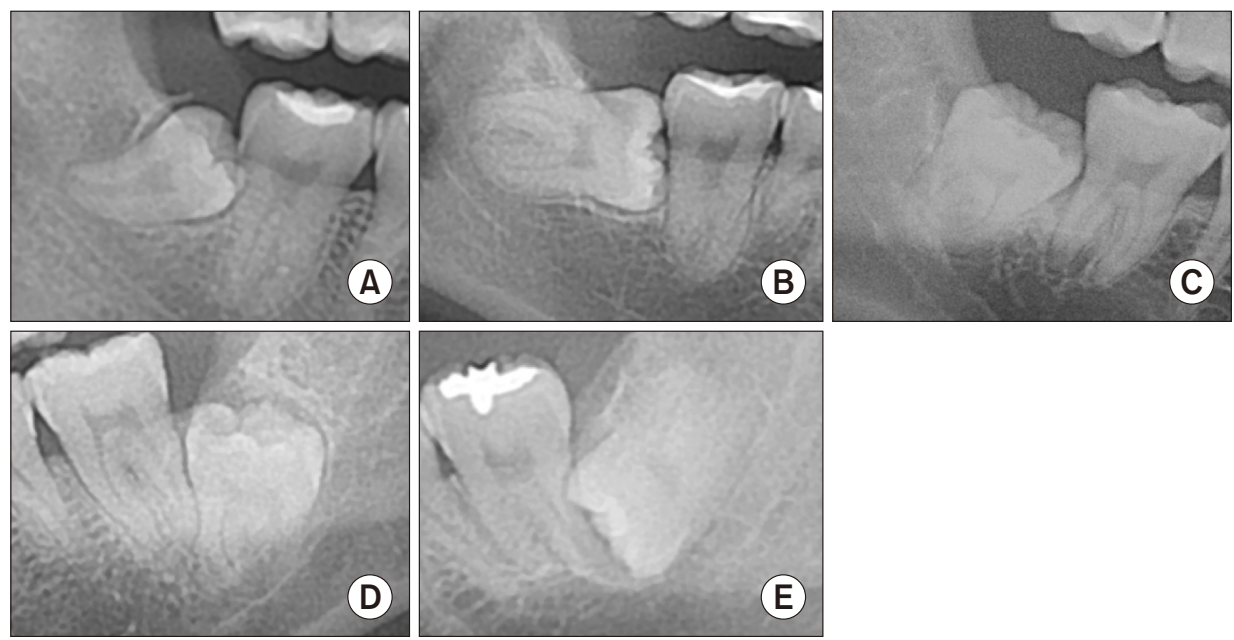

Fig. 2. Spatial relationship. Mesioangulated (A), horizontal (B), vertical (C), distoangulated (D), reverse mesioangulated (E) was defined when the long-axis of the third molar was impacted between $11^{\circ}$ to $79^{\circ}$. Horizontal and vertical were defined as cases where the angle between the adjacent second molar was $80^{\circ}$ to $100^{\circ}$ (almost perpendicular) and $-10^{\circ}$ to $10^{\circ}$ (almost parallel), respectively. When the long axis was $-11^{\circ}$ to $-79^{\circ}$, it was designated distoangulated. Reverse was defined when the crown of impacted third molar was more rootoriented than horizontal.

Jae-Young Kim et al: Modified difficult index adding extremely difficult for fully impacted mandibular third molar extraction. J Korean Assoc Oral Maxillofac Surg 2019 
sent was waived.

\section{Classification of the impacted third molar based on panoramic $x$-ray images}

One observer analyzed the panoramic x-ray images obtained twice at a minimum interval of one month. In the first analysis, the impacted third molar was classified by visual impression, whereas, in the second, medical software (ZeTTA PACS; Tae Young Soft, Anyang, Korea) was used for measurement.(Fig. 1) If there were a discrepancy between the two analyses, the measurement value from the second analysis was used.

Based on Winter's classification, the spatial relationship was subcategorized as mesioangulated (Mes), horizontal (Hor), vertical (Ver), distoangulated (Dis), or reverse (Rev) ${ }^{6,13}$. Cases where the angle between the adjacent second molar was $80^{\circ}$ to $100^{\circ}$ (almost perpendicular) and $-10^{\circ}$ to $10^{\circ}$ (almost parallel) were categorized as Hor and Ver, respectively. Cases where the inclination of the long axis of third molar was $11^{\circ}$ to $79^{\circ}$ and $-11^{\circ}$ to $-79^{\circ}$ were categorized as Mes and Dis, respectively. Cases where the crown of the impacted third molar were more root oriented than horizontal were categorized as $\operatorname{Rev}^{13}$.(Fig. 2)

Depth was subcategorized as levels A, B, C, or D.(Fig. 3) When more than half of the crown of the impacted third mo- lar was above the cervico-enamel junction (CEJ) of the adjacent second molar, it was defined as level A. When less than half of the presented crown was above the CEJ, it was defined as level B. When the entire crown of the impacted third molar was located below the CEJ of the adjacent second molar, it was defined as either level $\mathrm{C}$ or level D. Level $\mathrm{C}$ was defined as a condition when more than half of the impacted third molar crown was located superior to the mid-level of the adjacent second molar root. Third molar crown levels inferior to the aforementioned reference were categorized as level D.

The ramus relationship/space available was subclassified into three categories based on the calculated eruption space: class I, II, or III. Eruption space was calculated as the ratio of the distance between the ascending ramus to the distal side of the second molar (a) and diameter of the impacted third molar (b), as illustrated in Fig. 1. An eruption space (a/b) larger than two-thirds was classified as class I, between one-third and two-thirds was class II, and smaller than one-third was class III.(Fig. 4)

\section{Scoring}

According to the difficulty, the spatial relationship was scored on a scale of 1 to 5 as follows: Mes (1), Hor (2), Ver (3), Dis (4), and Rev (5) ${ }^{8}$. For depth, 1 to 4 points were assigned
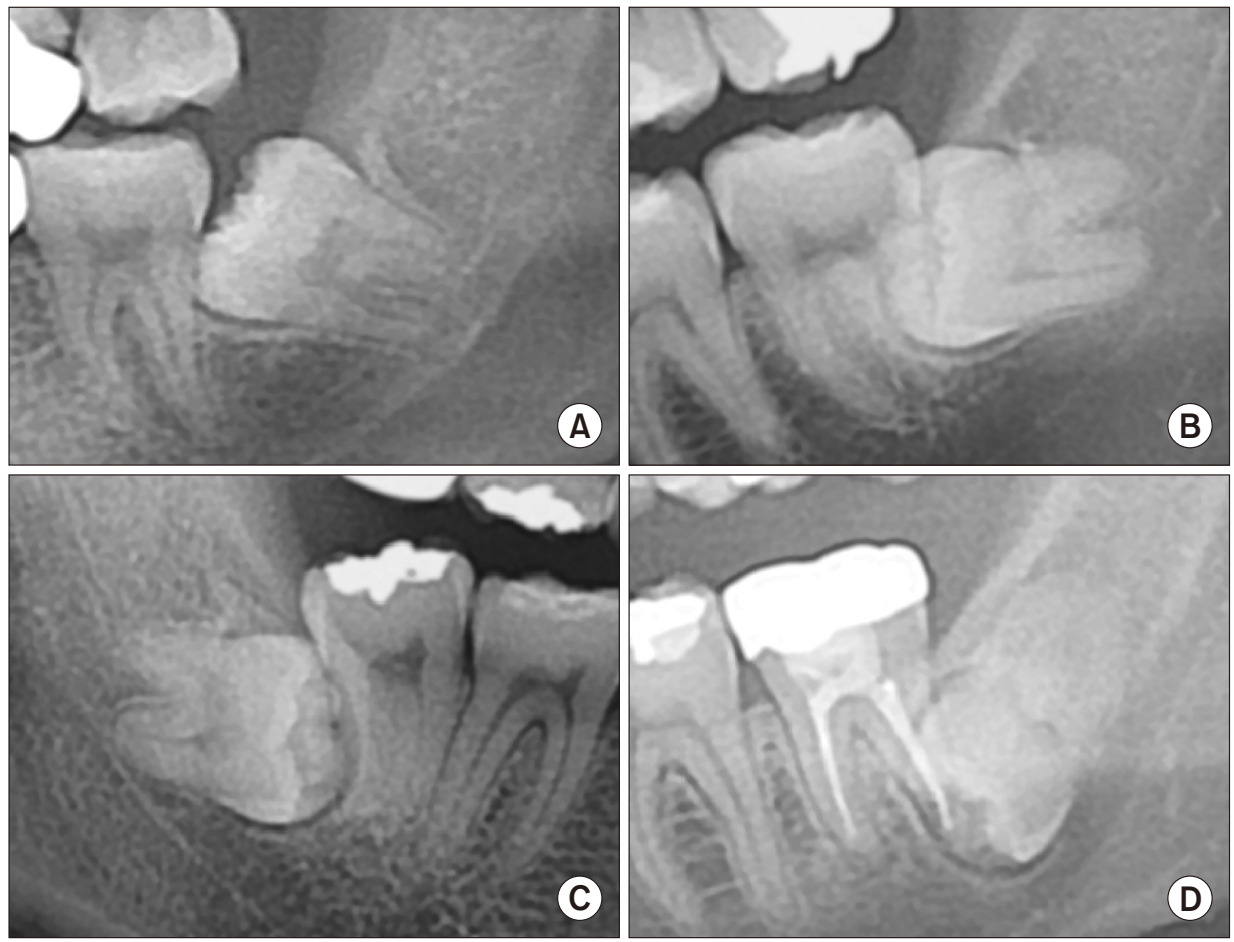

Fig. 3. Depth. A. Level A, when more than half of the crown of impacted third molar was existing above the cervicoenamel junction (CEJ) of the adjacent second molar. B. Level B, when less than half of the presented crown was above the CEJ. Level C (C) and Level $D$ (D), when the entire crown of the impacted third molar was located below CEJ of the adjacent second molar. Level C was defined as a condition when more than half of the impacted third molar crown was located superior to the mid-level of the adjacent second molar root. Third molar crown levels inferior to the aforementioned reference was categorized as level D.

Jae-Young Kim et al: Modified difficult index adding extremely difficult for fully impacted mandibular third molar extraction. J Korean Assoc Oral Maxillofac Surg 2019 

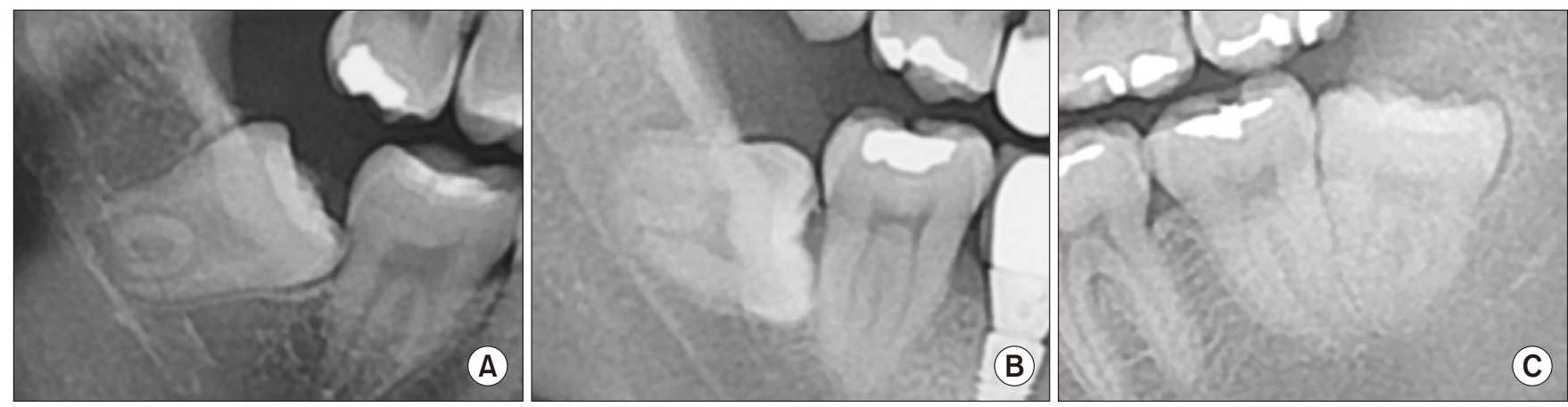

Fig. 4. Ramus relationship/space available. A. Class I. B. Class II. C. Class III. Eruption space was calculated as the ratio of the distance between the ascending ramus to the distal of second molar (a) and diameter of the impacted third molar (b), which was illustrated in Fig. 1. When eruption space (a/b) was larger than two-thirds, it was classified as class I, between one-third and two-thirds, it was classified as class II, and when smaller than one-third, it was classified as class III.

Jae-Young Kim et al: Modified difficult index adding extremely difficult for fully impacted mandibular third molar extraction. J Korean Assoc Oral Maxillofac Surg 2019

from levels A to D, respectively. Similarly, 1 to 3 points were given to classes I to III, respectively. The total points were calculated by adding the scores of each category.

\section{Difficulty index}

The difficulty index was classified into four categories according to the total points scored ${ }^{8}$. As in the previous method, scores up to 10 points were classified into three grades. One grade was added when the total points exceeded 10. Finally, four grades were defined as follows: category I (3-4 points, slightly difficult), category II (5-7 points, moderately difficult), category III (8-10 points, very difficult), and category IV (11-12 points, extremely difficult).

\section{Statistical analyses}

Quadratic weighted kappa analysis was used for categorical variables, and intra-class correlation coefficient analysis was used for continuous variables to analyze the intra-observer consistency. An independent t-test was used to analyze the age differences according to the sex of the patients included in the study. An ANOVA was performed to analyze the difference in age according to the difficulty index. Difference in sex and the difficulty index were analyzed using the chisquared test. The data were analyzed using a statistical analysis program (SAS ver. 9.3 [SAS Institute, Cary, NC, USA] and IBM SPSS Statistics ver. 23.0 [IBM, Armonk, NY, USA]). A $P$-value less than 0.05 indicated significance.

\section{Results}

Among 154 patients, 67 were males and 87 were female, with a mean age of 29.91 \pm 9.10 years (range, 19-64 years). There was no significant difference in age based on the sex (male: $30.18 \pm 8.97$ years, female: $29.70 \pm 9.22$ years; $P=0.747$ ).

Quadratic weighted kappa values ( $95 \%$ confidence interval) were 0.775 (0.684-0.866), 0.744 (0.673-0.815), and 0.663 (0.573-0.753) for spatial relationship, depth, and ramus relationship, respectively, indicating substantial agreement. The agreement for the total points calculated twice was 0.855 (0.813-0.888), indicating very high agreement. For the assessed difficulty index, the quadratic weighted kappa was 0.746 (0.655-0.837), indicating substantial agreement.

Of the 204 impacted mandibular third molars, 89 were impacted on the left side, and 115 were impacted on the right. Hor teeth were most common $(\mathrm{n}=88,43.1 \%)$, followed by Mes $(\mathrm{n}=80,39.2 \%)$. Rev type impaction was observed in 15 cases $(7.4 \%)$.

In the depth category, level B was observed in 105 out of 204 cases (51.5\%). Levels A and C were observed in 31 and 59 cases, respectively. In contrast, level D, which was not observed in the conventional classification by Pell and Gregory, was observed only in 9 cases (4.4\%), which is a relatively smaller percentage as compared to the other categories. Regarding the ramus relationship, 107 cases $(52.5 \%)$ belonged to class II, whereas class III was the second most common $(\mathrm{n}=78,38.2 \%)$.

When calculating the total points, a total of 6 was the most common ( 62 cases, 30.4\%), followed by 5 points ( 47 cases, $23.0 \%$ ) and 7 points (40 cases, $19.6 \%$ ). Only a few cases (13 
Table 1. Age, sex distribution, and pattern of impaction according to difficulty index

\begin{tabular}{|c|c|c|c|c|c|c|}
\hline & \multicolumn{4}{|c|}{ Difficulty index } & \multirow{3}{*}{ Total } & \multirow{3}{*}{$P$-valu } \\
\hline & \multicolumn{4}{|c|}{ Category } & & \\
\hline & I & II & III & IV & & \\
\hline No. of patients (\%) & $14(6.9)$ & $149(73.0)$ & $28(13.7)$ & $13(6.4)$ & $204(100)$ & \\
\hline Age (yr) & $25.64 \pm 6.30 *$ & $28.23 \pm 7.95 *$ & $31.82 \pm 9.57$ & $40.15 \pm 7.93$ & $29.31 \pm 8.64$ & $<0.001$ \\
\hline Sex & & & & & & 0.149 \\
\hline Male & 2 & 65 & 12 & 7 & 86 & \\
\hline Female & 12 & 84 & 16 & 6 & 118 & \\
\hline Spatial relation & & & & & & $<0.001$ \\
\hline Mesioangulated & 14 & 66 & 0 & 0 & 80 & \\
\hline Horizontal & 0 & 72 & 16 & 0 & 88 & \\
\hline Vertical & 0 & 8 & 0 & 0 & 8 & \\
\hline Distoangulated & 0 & 3 & 10 & 0 & 13 & \\
\hline Reverse & 0 & 0 & 2 & 13 & 15 & \\
\hline Depth & & & & & & $<0.001$ \\
\hline Level A & 9 & 22 & 0 & 0 & 31 & \\
\hline Level B & 5 & 92 & 8 & 0 & 105 & \\
\hline Level C & 0 & 35 & 17 & 7 & 59 & \\
\hline Level D & 0 & 0 & 3 & 6 & 9 & \\
\hline Ramus relation & & & & & & $<0.001$ \\
\hline Class I & 7 & 12 & 0 & 0 & 19 & \\
\hline Class II & 7 & 93 & 7 & 0 & 107 & \\
\hline Class III & 0 & 44 & 21 & 13 & 78 & \\
\hline
\end{tabular}

$* P<0.05$ compared to Category IV.

Difficulty index: Category I, slightly difficult; Category II, moderately difficult; Category III, very difficult; Category IV, extremely difficult.

Refer to Fig. 3 for the definition of depth category.

Refer to Fig. 4 for the definition of ramus relation.

Jae-Young Kim et al: Modified difficult index adding extremely difficult for fully impacted mandibular third molar extraction. J Korean Assoc Oral Maxillofac Surg 2019

out of $204,6.4 \%$ ) had a total of more than 10 points.

In terms of difficulty, category II (moderately difficult) was the most common (149 cases, $73.0 \%$ ) followed by category III (very difficult; 28 cases, 13.7\%), and there were 13 cases (6.4\%) of category IV (extremely difficult). The mean age was the highest in category IV (40.15 \pm 7.93 years) and was subsequently lower in each successive category: category III (31.82 \pm 9.57 years), category II (28.23 \pm 7.95 years), and category I (25.64 \pm 6.30 years) with a significant difference $(P<0.001)$. There was no significant difference between the difficulty index and sex $(P=0.149)$.(Table 1$)$

\section{Discussion}

It is important to recognize the difficulty and impaction pattern before an impacted mandibular third molar extraction because several investigators have reported that these could be associated with postoperative complications and subsequent treatment plans. According to Eshghpour and Nejat ${ }^{1}$, a difficulty score based on radiography was associated with the incidence of a dry socket. Ishii et $\mathrm{al}^{2}$ reported that the horizontal inclination angle is associated with the risk of inferior alveolar nerve injury during mandibular third molar extraction. General anesthesia accompanying more complicated procedures is required for a more deeply impacted tooth ${ }^{14}$.

Several studies on impacted third molars used the difficulty index described by Pederson ${ }^{7}$ to predict the difficulty of the impacted third molar extraction ${ }^{7-9}$. This index was developed based on the Pell and Gregory classification ${ }^{5}$ and the Winter's classification $^{6}$. However, the classification categories of the difficulty index are not always perfectly applicable in clinical situations. Therefore, the purpose of this study was to evaluate the validity of the classification of the impacted mandibular third molar in clinical situations and propose a more practical classification system.

In this study, patients under 19 years old were excluded in accordance with the previous study ${ }^{15,16}$. Impacted teeth accompanied with pathologic conditions, such as cysts, were also excluded because the impacted third molars could migrate because of the pathologic lesions. According to Quek et al. ${ }^{13}$, the spatial relationship (angulation) of the impacted third molar was still analyzed via visual impression based on Winter's classification. In this study, we used visual impression in the first analysis and conducted a follow-up measurement using medical software for a more objective judgment in the second analysis to compare the agreement of these different methods.

Since there were three to five subcategories, we used a 
quadratic weighted kappa value. For all categories, the kappa value was over 0.6 , which indicated substantial agreement between visual impression and software measurement ${ }^{17}$. Therefore, as Quek et al. ${ }^{13}$, we considered visual impression a reliable method to determine the degree of impaction.

In the current difficulty index described by Pederson ${ }^{7}$, there are four grades for spatial relationship, three for depth, and three for the ramus relationship/space described. The level of difficulty was defined by three grades depending on the score: slightly difficult (3-4), moderately difficult (5-7), and very difficult (8-10). In our study, we added Rev and level D, which are not included in the currently used difficulty index ${ }^{8}$. Thus, one more advanced category (category IV: extremely difficult) was added in the difficulty index.

According to the results of this study, Hor impaction was the most common angulation type, consecutively followed by Mes and Ver. Previous studies reported Mes as the most common type in Iranian and Singapore Chinese populations ${ }^{13,16}$. This difference is presumed to be due to a different study population because every mandibular third molar in our study had more than two-thirds of the crown impacted. Additionally, we presumed that relatively simple cases were extracted in private clinics, not in a medical facility like our hospital, which is a tertiary medical institution. In the depth category, level B was the most common type, as is consistent with the findings of previous studies ${ }^{13,18}$.

In this study, the mean age was highest in category IV and lowest in category I. It is presumed that deeply impacted third molars have a relatively lower probability of causing discomfort or further problems, including pericoronitis; hence, patients would delay a visit to the hospital for an impacted third molar. Gbotolorun et al. ${ }^{10}$ reported the importance of clinical variables such as age, body mass index, and root curvature in predicting surgical difficulty. Therefore, considering the age of the patient, the extraction of teeth in patients in category IV could be much more difficult.

In the future, it is necessary to record the actual extraction time according to the classification category to determine the prediction value of this updated classification system.

\section{Conclusion}

The authors propose a four-step difficult index because the clinician should consider one more extremely difficult category beyond the existing three-step difficulty index to make a treatment plan for extracting wisdom teeth. The patient's age should be taken into consideration while evaluating the difficulty of extraction.

\section{ORCID}

Jae-Young Kim, https://orcid.org/0000-0002-9423-438X

Hae-Sung Yong, https://orcid.org/0000-0001-8671-4175

Kwang-Ho Park, https://orcid.org/0000-0003-1942-2986

Jong-Ki Huh, https://orcid.org/0000-0002-7381-3972

\section{Authors' Contributions}

J.Y.K. collected data and wrote a manuscript. H.S.Y. collected data and participated in statistical analysis. K.H.P. participated in study design and provided figures. J.K.H. participated in study design and drafted the manuscript. All authors read and approved the final manuscript.

\section{Acknowledgements}

We would like to thank Hye Sun Lee (PhD, Biostatistician) and Sinae Kim (MS Biostatistician) of the Biostatistics Collaboration Unit, Yonsei University College of Medicine, Seoul, Korea for their help with the statistical analyses.

\section{Ethics Approval and Consent to Participate}

This retrospective study was approved by the Institutional Review Board of the Gangnam Severance Hospital (approval No. 3-2019-0118), and the informed consent was waived.

\section{Conflict of Interest}

No potential conflict of interest relevant to this article was reported.

\section{References}

1. Eshghpour M, Nejat AH. Dry socket following surgical removal of impacted third molar in an Iranian population: incidence and risk factors. Niger J Clin Pract 2013;16:496-500.

2. Ishii S, Abe S, Moro A, Yokomizo N, Kobayashi Y. The horizontal inclination angle is associated with the risk of inferior alveolar nerve injury during the extraction of mandibular third molars. Int J Oral Maxillofac Surg 2017;46:1626-34.

3. Lee YK, Park SS, Myoung H. Surgical extraction of mandibular third molar in pterygomandibular space: a case report. J Korean Assoc Oral Maxillofac Surg 2013;39:242-5.

4. Kupferman SB, Schwartz HC. Malposed teeth in the pterygomandibular space: report of 2 cases. J Oral Maxillofac Surg 2008;66:167-9.

5. Pell G, Gregory B. Impacted mandibular third molars: classification 
and modified techniques for removal. Dent Digest 1933;39:330-8.

6. Winter GB. Principles of exodontia as applied to the impacted mandibular third molar. St. Louis: American Medical Book Company; 1926.

7. Pederson GW. Oral surgery. Philadelphia: WB Saunders, 1988.

8. Koerner KR. The removal of impacted third molars. Principles and procedures. Dent Clin North Am 1994;38:255-78.

9. Yuasa H, Kawai T, Sugiura M. Classification of surgical difficulty in extracting impacted third molars. Br J Oral Maxillofac Surg 2002;40:26-31.

10. Gbotolorun OM, Arotiba GT, Ladeinde AL. Assessment of factors associated with surgical difficulty in impacted mandibular third molar extraction. J Oral Maxillofac Surg 2007;65:1977-83.

11. Sammartino G, Gasparro R, Marenzi G, Trosino O, Mariniello M, Riccitiello F. Extraction of mandibular third molars: proposal of a new scale of difficulty. Br J Oral Maxillofac Surg 2017;55:952-7.

12. García AG, Sampedro FG, Rey JG, Vila PG, Martin MS. PellGregory classification is unreliable as a predictor of difficulty in extracting impacted lower third molars. Br J Oral Maxillofac Surg 2000;38:585-7.

13. Quek SL, Tay CK, Tay KH, Toh SL, Lim KC. Pattern of third molar impaction in a Singapore Chinese population: a retrospective radiographic survey. Int J Oral Maxillofac Surg 2003;32:548-52.
14. Abu-El Naaj I, Braun R, Leiser Y, Peled M. Surgical approach to impacted mandibular third molars--operative classification. J Oral Maxillofac Surg 2010;68:628-33.

15. Fielding AF, Douglass AF, Whitley RD. Reasons for early removal of impacted third molars. Clin Prev Dent 1981;3:19-23.

16. Eshghpour M, Nezadi A, Moradi A, Shamsabadi RM, Rezaei NM, Nejat A. Pattern of mandibular third molar impaction: a cross-sectional study in northeast of Iran. Niger J Clin Pract 2014;17:673-7.

17. Landis JR, Koch GG. The measurement of observer agreement for categorical data. Biometrics 1977;33:159-74.

18. Padhye MN, Dabir AV, Girotra CS, Pandhi VH. Pattern of mandibular third molar impaction in the Indian population: a retrospective clinico-radiographic survey. Oral Surg Oral Med Oral Pathol Oral Radiol 2013;116:e161-6.

How to cite this article: Kim JY, Yong HS, Park KH, Huh JK Modified difficult index adding extremely difficult for fully impacted mandibular third molar extraction. J Korean Assoc Oral Maxillofac Surg 2019;45:309-315. https://doi.org/10.5125/jkaoms.2019.45.6.309 